\title{
Intolerância religiosa: um estudo sobre as divergências das concepçóes da legitimidade da doutrina do Santo Daime
}

Ronaldo Emiliano de Miranda ${ }^{1}$

\begin{abstract}
Resumo: $\mathrm{O}$ artigo propóe estudar, analisar e discutir as intolerâncias enfrentadas pela religião do Santo Daime, desde sua fundação, em 1930, pelo maranhense Raimundo Irineu Serra, até o seu desenvolvimento atual. É uma religião genuinamente brasileira, de tradição oral, que teve seu início a partir da ressignifação ritualística da Ayahuasca, rebatizada como Daime, pelo seu fundador. A construção e a sedimentação da religião daimista ocorrem de forma gradativa, até o falecimento do Mestre Irineu. Logo após o seu falecimento, houve uma dissidência interna de opinióes sobre a doutrina, quanto à legitimidade de suas práticas rituais e costumes, o que resultou no surgimento de duas vertentes daimistas, que geraram as tensóes e a intolerância interna. A religião daimista usa, em seus rituais, a Ayahuasca (Daime), um chá de origem xamânica, de uso milenar. Fora da igreja daimista, o Daime é considerado uma droga com propriedades alucinógenas, o que gera bastante polêmica e motiva inúmeras intolerâncias no país e no exterior. Apesar disso, o Santo Daime conseguiu uma expansão nacional e internacional. O texto procurou apontar para os avanços, a necessidade da compreensão e a percepção de uma boa convivência com a pluralidade religiosa. Buscou, também, viabilizar o diálogo inter-religioso e, consequentemente, fortalecer o "direito sagrado de divergir". A metodologia empregada na construção deste artigo foi baseada em pesquisas bibliográficas de livros, artigos, dissertaçóes e teses de autores conceituados e sítios oficiais das vertentes da religião daimista.
\end{abstract}

Palavras-chave: Alucinógeno; Amazônia; Daime; Mestre Irineu; Padrinho Sebastião.

\footnotetext{
1 Mestrando no Programa de Pós-Graduação em Ciências da Religião da PUC Minas.
} 


\title{
Religious Intolerance: a study on the divergences in the conceptions of the legitimacy of the Santo Daime doctrine
}

\begin{abstract}
The article proposes to study, analyze and discuss the intolerances faced by the Santo Daime religion, since its foundation in 1930, by Raimundo Irineu Serra, from Maranhão state, Brazil, until its current development. It is a genuinely Brazilian religion of oral tradition, which began with the ritualistic redefinition of Ayahuasca, renamed Daime by its founder. The construction and sedimentation of the daime religion took place gradually until the death of Master Irineu. Shortly after his death, there was an internal dissent of opinions about the doctrine, regarding the legitimacy of its ritual practices and customs, which resulted in the emergence of two daime strands, which generated internal tensions and intolerance. The daimista religion uses Ayahuasca (Daime) in its rituals, a millenary tea of shamanic origin. Outside the daime church, the Daime is considered a drug with hallucinogenic properties, which generates a lot of controversy and motivates countless intolerances in the country and abroad. Despite this, Santo Daime achieved national and international expansion. The text sought to point out the advances, the need for understanding and the perception of a good coexistence with religious plurality; it also sought to enable inter-religious dialogue, and consequently strengthen the "sacred right to diverge". The methodology used in the writing of this article is based on bibliographical research of books, articles, dissertations and theses by renowned authors and official websites of the diarist religion.
\end{abstract}

Keywords: Hallucinogen; Amazon; Daime; Master Irineu; Godfather Sebastião. 


\section{Introduçáo}

O presente artigo tem por objetivo estudar e discutir as intolerâncias enfrentadas pela religiáo do Santo Daime, Religião da Floresta, desde a fundação, em 1930, pelo maranhense Raimundo Irineu Serra, até o seu desenvolvimento atual. A religião daimista, genuinamente brasileira, de tradição oral, teve o seu início a partir da concepção do novo significado ritualístico da Ayahuasca ${ }^{2}$, rebatizada como Daime, pelo seu fundador. O Daime é uma bebida indígena, um chá xamânico, que contém uma substância psicoativa e $e^{3}$ às vezes, é interpretado de forma equivocada como alucinógeno ${ }^{4}$. Porém, os daimistas o concebem como enteógeno ${ }^{5}$.

A construção e a sedimentação da religião do Santo Daime ocorreram de forma gradativa, até o falecimento do Mestre Irineu, em 1971. Após o seu falecimento, ocorreu uma dissidência interna de opiniōes na doutrina, até então, tida como homogênia e ortodoxa e, dessa maneira, surgiram as tensôes e a intolerância interna. A partir daí, originaram-se duas vertentes daimistas, cada uma defendendo o seu ponto de vista particular sobre a legitimidade da religião daimista. A intolerância externa está associada à ligação da religiáo do Santo Daime com as bricolagens de elementos religiosos cristãos com os da tradição indígena, principalmente pelo uso ritualístico do Daime (Ayahuasca). Essas práticas geram muitas polêmicas. Daí, surgiram as intolerâncias no Brasil e no Exterior quanto à aceitação da religião do Santo Daime.

O texto é um ensaio e uma tentativa de se compreender como uma religiáo, essencialmente oral, originária da regiâo fronteiriça da Amazônia, conseguiu uma expansão nacional e internacional, enfrentando os dilemas mencionados. Serão abordados também os avanços ocorridos no Brasil e no exterior, que legitimam a religião do Santo Daime como verdadeira e pertencente ao grupo de religióes mundiais, merecendo o seu devido respeito. A metodologia utilizada na construção do artigo é baseada em pesquisas bibliográficas de livros de autores conceituados, artigos, dissertaçóes e teses produzidas por acadêmicos renomados e sítios oficiais das vertentes. O artigo buscará demonstrar, através dos argumentos expostos, como é possível, diante da diversidade religiosa e de visóes antagônicas, delinear uma boa compreensão sobre os fundamentos das vertentes daimistas, facilitar o diálogo inter-religioso e, consequentemente, fortalecer o direito sagrado de divergir.

\footnotetext{
2 Ayahuasca é um chá indígena, de uso milenar, com propriedades psicoativas, obtido através da decoç̧ão do cipó (Banisteriopsis caapi) ou "jagube" e da folha do arbusto (Psychotria viridis), denominada pelos daimistas como "Rainha" ou chacrona. Na língua Quéchua, Ayahuasca significa "trepadeira das almas" ou "liana (cipó) dos espíritos" (Cf. LABATE, 2004 apud ASSIS; LABATE, 2014, p. 13).

3 Substância psicoativa ou psicoativo entende-se como uma substância que ativa a psique ou age sobre ela. (MACRAE, 1992, p. 16).

4 Alucinógeno entende-se como uma substância que possa produzir uma alucinação. Alucinar significa errar, enganar-se, privar da razão, do entendimento, desvairar, aloucar. (MACRAE, 1992, p. 16).

5 Enteógeno é um termo derivado da palavra entheos, de origem grega, que significa literalmente "deus dentro" e é utilizada para descrever o estado em que alguém se encontra quando inspirado ou possuído por um deus que entrou em seu corpo. Portanto, enteógeno significa aquilo que leva alguém a ter o divino dentro de si. (MACRAE, 1992, p. 16).
} 


\section{Origem, fundaçáo e sedimentaçáo da religiáo do Santo Daime no Brasil}

A partir do final do século XIX e início do século XX, ocorreu um importante movimento migratório, quando uma inesperada quantidade de pessoas abandonou a precária agricultura de subsistência no Nordeste, principalmente no Estado do Ceará e Maranhão, para se dedicar à extração da borracha, nos seringais da Amazônia, na região fronteiriça entre Brasil, Peru e Bolívia. Tal movimento ficou conhecido como o $1^{\circ}$ (primeiro) Ciclo da Borracha, que prometia um enriquecimento rápido no Norte do país, o que levou aquela regiáo amazônica a enfrentar fortes impulsos desenvolvimentistas. Esse contingente de pessoas teve que se adaptar às leis da Floresta e enfrentar a malária, os animais ferozes, a resistência dos índios nativos aos invasores de suas terras e a vontade exacerbada dos senhores seringalistas de prosperarem. Esses últimos, por sua vez, eram grandes latifundiários, que desejavam se enriquecer com a extração do látex, para atenderem à crescente demanda de borracha pela indústria internacional. (MOREIRA; MACRAE, 2011, p. 79).

Essa regiáo fronteiriça amazônica, do lado brasileiro, naquela época, possuía escassos recursos para o atendimento médico, existindo apenas como opçóes os remédios caseiros, que nem sempre eram muito efetivos, e, nos momentos mais complicados, só restava recorrer aos trabalhos dos rezadores, à pajelança indígena ou mestiça e inclusive aos vegetaristas. (MOREIRA; MACRAE, 2011, p. 57).

Entáo, dentro desse contexto socioeconômico e incentivado pelos rumores de que, no Amazonas, estavam contratando pessoas para trabalhar nos seringais, para a extração da borracha, e de que se fazia muito dinheiro lá, Raimundo Irineu Serra migrou-se para lá, em 1912. Mestre Irineu, assim conhecido no meio de sua comunidade, é descrito como negro, alto, forte e neto de escravos. Fixou-se inicialmente em Xapuri, onde residiu por dois anos. Três anos depois, trabalhou nos seringais da Brasileia e outro tanto em Sena Madureira ${ }^{6}$. Naquela época, trabalhou também como funcionário da Comissão de Limites ${ }^{7}$, na região amazônica fronteiriça. Nos anos em que passou trabalhando na floresta amazônica, aprofundou o seu conhecimento a respeito da população cabocla local e de sua cultura. Nessa época, teve como companheiros os irmãos Antônio e André Costa, seus conterrâneos maranhenses. Através deles, tomou conhecimento do uso da Ayahuasca na cidade de Cobija, na Bolívia, região fronteiriça com o Brasil (no Estado do Acre). (MACRAE, 1992, p. 61-62).

Segundo Oliveira (2007, p. 136), entre os povos indígenas, tem-se a concepção de que, a partir da ingestão da Ayahuasca, torna-se possível o contato com os espíritos dos antepassados e da natureza. .

Portanto, ao beber a Ayahuasca, por volta do ano 1912 ou 1914, Raimundo Irineu Serra teve revelaçóes psíquicas e espirituais que o conduziram, nos anos posteriores, a organizar uma

\footnotetext{
6 Xapuri, Brasileia e Sena Madureira são municípios no sul do Estado do Acre. (Fonte: dados do mapa Google 2021. Disponível em: https:// www.google.com/maps/place/Xapuri. Acesso em: 04 jan. 2021).

7 Comissão de Limites, criada pelo Governo Federal, para serviços de delimitação da fronteira do Acre com a Bolívia e o Peru. (MOREIRA; MACRAE, 2011, p. 112).
} 
nova forma de trabalho com essa bebida indígena. Sob sua direção, a partir da década de 30, na cidade de Rio Branco (Acre), deu-se início ao processo de formação da doutrina daimista, quando a bebida foi rebatizada, pelo seu fundador, conhecido na comunidade como Mestre Irineu. O Mestre introduziu uma nova técnica para o preparo do chá e criou os principais rituais e símbolos da religiáo, que passaram a ser os fundamentos doutrinários do Santo Daime. (OLIVEIRA, 2007, p. 33). Com o passar dos anos, a partir da divulgação das narrativas que relatavam curas, bênçáos e feitos miraculosos pelo uso da bebida sacramental, divulgadas no meio dos seguidores, foi se formando um novo entendimento sobre o nome da Ayahuasca, rebatizada pelo Mestre como Daime ${ }^{8}$, e, com o tempo, passou a ser denominada como Santo Daime. (OLIVEIRA, 2007, p. 76).

Assim sendo, o Mestre Raimundo Irineu, no que lhe concerne, parece ter se submetido ao processo de iniciaçáo e de conhecimento da tradição xamânica dos ayahuasqueros e vegetalistas da Amazônia. A partir de tais experiências, os irmãos Costa abriram um centro, na década de 1920, chamado Círculo de Regeneração e Fé (CRF), instalado na cidade de Brasileia. Desse grupo, participava também o Mestre Irineu Serra. Hoje, o CRF, é considerado, pelos adeptos daimistas, como precursor do Daime. (MACRAE, 1992, p. 62).

A Ayahuasca era usada pelas populaçóes nativas da região amazônica brasileira e andina, para diferentes finalidades, dentre elas, pode-se dizer para diagnóstico de doenças, adivinhação, proteção para boas caçadas, preparação para guerra, práticas xamânicas e de curandeirismo (MACRAE, 1992, p. 28).

Segundo MacRae (1992, p. 62), dentre as primeiras experiências do Mestre Irineu ao fazer uso da Ayahuasca, a principal foi o relato das visóes repetidas da aparição de uma entidade feminina, denominada Clara, que, posteriormente, ele identificou como sendo a Nossa Senhora da Conceição, ou a Rainha da Floresta. Durante essas apariçóes, segundo Irineu, a entidade lhe teria dado instruçóes a respeito de uma dieta que deveria seguir, preparando-se para o recebimento de uma missáo especial, de se tornar um grande curador.

Outro episódio que costuma ser relatado, mencionado por MacRae (1992, p. 64), é a visão que o Mestre Irineu teve da lua se aproximando dele, trazendo em seu Centro uma águia. Segundo o relato, era a Nossa Senhora que vinha "entregar os seus ensinos (transmissão de conhecimentos)". Essa "miração" teve uma grande importância para o desenvolvimento do trabalho de Mestre Irineu e passou a constituir o tema do seu primeiro hino, além de fornecer um dos principais símbolos do culto daimista. A lua representa a ideia de que a doutrina foi ensinada pela Virgem Mãe e a águia faz alusão ao grande poder de visão que é dado aos seus seguidores.

\footnotetext{
8 O nome Daime vem das invocaçóes “dai-me luz" ou "daí-me amor", usadas pelos participantes dos rituais daimistas. (MIRANDA, 2020). Tais invocaçôes estão presentes no hino no 41 "Estrela D’água”, do Mestre Irineu. (MATOS DA SILVA, 1994).

9 A origem do termo miração pode estar relacionada à palavra "mareação", utilizada pelos curandeiros da Alta Amazônia Peruana (regiāo de San Martin). Nesse contexto, a palavra define o estado mental que se segue à ingestáo da Ayahuasca, abarcando também as ideias de embriaguez e visão. (Cf. MABIT, 2004, p. 156 apud OLIVEIRA, 2007, p. 142).
} 
Utilizando-se da visão de Berger (2004), pode-se conceber a miração do Mestre Irineu da seguinte forma:

A "receita" fundamental da legitimação religiosa é a transformação de produtos humanos em facticidades supra-humanas ou não-humanas. $\mathrm{O}$ mundo feito pelo homem é explicado em termos que negam sua produção pelo homem. $\mathrm{O}$ nomos humano torna-se um cosmos divino, ou, pelo menos, uma realidade cujos significados são derivados de fora da esfera humana. (BERGER, 2004, p. 102).

Pouco tempo depois, segundo MacRae, o Mestre Irineu mudou-se para Sena Madureira, transferindo-se em 1920, para a cidade de Rio Branco, no Acre, onde ingressou na Guarda Florestal. Permaneceu nessa corporação até 1932, quando deu baixa com a graduação de Cabo. Porém, em 1930, residindo no bairro de Vila Ivonete, zona rural de Rio Branco, iniciou os trabalhos públicos com o Daime (Ayahuasca). Inicialmente, o Mestre Irineu tornou-se conhecido dentro da pequena comunidade local, cujos membros constituía a maior parte de seus seguidores. Com o passar dos anos, sua doutrina foi se consolidando e as sessóes começaram a ser frequentadas por outras pessoas, inclusive de raças diferentes. Dessa maneira, os seus poderes de cura passaram a ser divulgados, tornando-se conhecidos em toda a região, até o ponto em que as autoridades locais passaram a se interessar pela doutrina. Assim sendo, o Mestre Irineu, já conhecido, contava com a amizade e o apoio de personagens influentes na política local, como o coronel Fontanelle de Castro e o governador do Acre, Guiomard dos Santos. Segundo Couto (1989), embora essas autoridades não tomassem o Daime, gostavam de aparecer ao lado do Mestre Irineu, em épocas eleitorais. (Cf. COUTO, 1959, p. 58 apud MACRAE, 1992, p. 64-65).

MacRae enfatiza que, devido à influência do governador Guiomard, o Mestre Irineu obteve, na década de 1940, a doação da Colônia Custódio de Freitas, situada na zona rural de Rio Branco, cujas terras foram divididas entre as famílias frequentadoras do culto daimista. A partir dessa época, essa colônia passou a ser conhecida como Alto Santo, onde foi construída uma Igreja-sede do culto, batizada de Centro de Iluminação Cristã Luz Universal (CICLU), com uma grande Cruz de Caravaca em cimento. (MACRAE, 1992, p. 65-66).

Mais tarde, em 1963, foi fundado o CICLU/Alto Santo, que foi liderado pelo Mestre Irineu, até o seu falecimento, em julho de 1971. Logo pós o seu falecimento, ocorreram disputas e algumas segmentaçôes dentro da organização. Inicialmente, Leôncio Gomes tornou-se o dirigente do CICLU. Hoje, segundo a Comunidade do Alto Santo (2021), ainda é comandado pela viúva de Irineu, Peregrina Gomes Serra, conhecida por "Madrinha Peregrina”. Por outro lado, Sebastiáo Mota de Melo, o Padrinho Sebastião, um dos principais discípulos do Mestre Irineu, se desvinculou do CICLU, por divergências com Leôncio, e passou a construir a sua própria comunidade, a vertente do Centro Eclético da Fluente Luz Universal Raimundo Irineu Serra (CEFLURIS), fundada em 1974. Hoje é comandada pelo seu filho, Alfredo Gregório de Melo, conhecido por "Padrinho Alfredo". Porém, vale destacar que a CEFLURIS manteve as bases dos rituais, as fardas e os principais hinários, mas agregou outros elementos kardecistas e umbandistas aos rituais daimistas. (ASSIS; LABATE, 2014, p. 13-14). 
Dessa maneira, o Santo Daime tornou-se uma religião brasileira, tida por seus seguidores como cristâ, formada no Estado do Acre. Suas Igrejas e comunidades filiadas à vertente CEFLURIS estão espalhadas por diversos estados do Brasil e em vários países do mundo, dentre eles, destacam-se: Estados Unidos, Espanha, Holanda, Itália, Alemanha, França, Inglaterra, Argentina, Chile, Japão e outros. (OLIVEIRA, 2007, p. 31).

Cabe evidenciar que o Santo Daime é uma religião de cultura essencialmente oral, cujos sentidos e práticas rituais são construídos e se perpetuam por meio de narrativas transmitidas oralmente, principalmente através dos hinários recebidos e passados de geração a geração. $\mathrm{O}$ processo de construção social de sentidos, na religiáo daimista, passa por um diálogo constante entre os seus adeptos, através das narrativas orais transmitidas para as geraçóes futuras. Portanto, segundo Oliveira, ao longo da história da religião do Santo Daime, esse diálogo com as narrativas orais fundamentou a ressignificação da Ayahuasca e a construção do significado atual da bebida. (OLIVEIRA, 2007, p. 65).

Essa teia de significados, segundo Oliveira (2007), surgiu das narrativas orais e passou a ter, como nos indica Berger (2004), uma facticidade, "um status de realidade objetiva, onde as pessoas passam a dialogar, a assimilar e a interagir para construir sua compreensão do presente da religiáo". (OLIVEIRA, 2007, p. 150). Assim, esses "fatos" construídos a partir dos argumentos discursivos passam a fazer parte da cultura atualizada da religiáo daimista. "Em outras palavras, o mundo cultural não só é produzido coletivamente como também permanece real, em virtude do reconhecimento coletivo. Estar na cultura significa compartilhar com os outros um mundo particular de objetividades". (BERGER, 2004, p. 23-24).

Oliveira (2007, p. 40) enfatiza que o Daime, uma substância psicoativa, é uma bebida que conduz as pessoas a um contato profundo com aspectos além da realidade, que transcendem a compreensão humana racional e sua experiência cotidiana. Portanto, o estado ampliado [alterado] de consciência, mediado pelo Daime, é denominado pelos seguidores daimistas de miração. Nessa situação, de acordo com cada pessoa, dentro da sua experiência singular, podem ocorrer diferentes percepçóes visuais, tanto com os olhos abertos, quanto fechados. Essa miração pode contemplar, entre outras experiências, por exemplo, o aumento da intuição; da sensibilidade estética, olfativa e auditiva; viagens astrais ${ }^{10}$; e comunicaçáo com espíritos, como no relato da experiência do Mestre Irineu com a bebida, por ocasião de seu encontro com a Virgem Maria. Acrescente-se a isso a percepção de uma experiência do "conhecimento", caracterizada pela sensação de se estar alcançando o "conhecimento verdadeiro" sobre um determinado assunto. (OLIVEIRA, 2007, p. 142).

Dentro dessa concepção, compreende-se que se trata de uma experiência de "êxtase"11 e também de uma outra perspectiva marginal, que proporciona esse contato com algo que escapa à realidade cotidiana. Berger aponta para o fato de que a religiáo mantém "a realidade

\footnotetext{
${ }^{10} \mathrm{Na}$ compreensão dos seguidores, as "viagens astrais" são momentos em que o espírito da pessoa se desprende do corpo e vai conhecer a realidade espiritual, genericamente conhecida como astral. (Cf. nota de rodapé 89, OLIVEIRA, 2007, p. 142).

${ }^{11}$ Êxtase, no sentido literal "estases, que quer dizer ficar, ou sair para além da realidade, como é definida comumente" (BERGER, 2004, p. 56).
} 
socialmente definida legitimando as situaçóes marginais em termos de uma realidade sagrada de âmbito universal" (BERGER, 2004, p. 57). No que concerne à religiáo do Santo Daime, consumidora da substância psicoativa, Ayahuasca (Daime), por meio de suas práticas, regras, rituais, hinários e fundamentos filosóficos, contribui para estruturar e conduzir a compreensão das experiências visionárias. Tudo isso são ferramentas simbólicas, segundo a compreensão de Oliveira, para lidar com o "espaço de mistério", as percepçôes ampliadas ou os estados alterados de consciência que essa substância revela. A doutrina daimista concebe como sagrados tanto o ato de ingerir o Daime, quanto a própria bebida, com os seus poderes visionários. Essa compreensão torna o Daime santo aos olhos de quem o concebe como instrumento extático, como veículo mediador de contato com essa realidade sagrada. Daí surge a ideia de Santo Daime (OLIVEIRA, 2007, p. 40).

É importante enfatizar que, entre as práticas nativas com a Ayahuasca, estudadas por diversos autores, verificou-se a presença de cânticos entoados durante o consumo do chá xamânico e, dessa maneira, ao que parece, contribuíam para as percepçóes das visóes relatadas, bem como estimulavam a comunicação com os espíritos. Esses cânticos são denominados pela população indígena como ícaros ${ }^{12}$, sendo que sua função ritual, conforme a concepção das populaçôes estudadas, seria conduzir as visóes e a força psicoativa da Ayahuasca. (OLIVEIRA, 2007, p. 137). Provavelmente as cançóes podem ter sido assimiladas pelo Mestre Irineu, ao longo de seu contato com a Ayahuasca, no contexto nativo, onde o consumo da bebida está associado à execução de cânticos simples, os ícaros. (OLIVEIRA, 2007, p. 187). Por outro lado, os seguidores daimistas compreendem os hinários não apenas como mensagens similares às palavras bíblicas, mas também como sua continuidade legítima, viva e atual, revelada e interpretada à luz do Espírito Santo e do chá sacramental, na religiáo do Santo Daime. (OLIVEIRA, 2007, p. 242).

Dito isso, cabe evidenciar que, segundo Oliveira, em relação às reaçôes no corpo físico dos adeptos, ao utilizarem o Daime (Ayahuasca) nos rituais, podem ocorrer naturalmente efeitos purgativos, laxantes e eméticos (vômitos), concebidos como "limpezas" que a bebida faz no corpo das pessoas. (OLIVEIRA, 2007, p. 138).

Agora, dentro do conjunto de símbolos daimistas, cabe destacar a cruz, que remete à primeira experiência visionária do Mestre Irineu. A cruz utilizada na religião daimista possui dois braços, conhecida na tradição cristã como Cruz de Caravaca. Assim sendo, o cruzeiro tornou-se o símbolo mais importante da religiāo do Santo Daime. Isso é tão relevante que o hino no 93, do Mestre Irineu, recebeu o nome de "O Cruzeiro" e diz: "No cruzeiro tem rosário. Para quem quiser rezar.” (OLIVEIRA, 2007, p. 161-162). Um outro símbolo, com um significado singular na visão daimista, é conceber a Clara como sendo a própria Virgem Maria da Conceição, conhecida e representada, também, como a Rainha da Floresta. (OLIVEIRA, 2007, p. 186). Portanto, os símbolos do Cruzeiro e do Rosário reforçam a compreensão de

\footnotetext{
12 Os ícaros são canções com uma melodia e uma letra simples, que se acredita que sejam ensinados pelos seres divinos que habitam em diversos elementos da natureza, tais como animais, pedras e plantas. São entoados para modular e dirigir a força psicoativa da Ayahuasca. (OLIVEIRA, 2007, p. 187).
} 
que são dois elementos que sugerem as representaçôes de Jesus e Virgem Maria, sua mãe. Essa concepção dos seguidores daimistas remete à compreensão da união do Mestre Irineu com a Rainha da Floresta. (OLIVEIRA, 2007, p. 221). Um outro símbolo utilizado na doutrina do Santo Daime é a Estrela, que representa a Estrela de Davi, também conhecida como Selo de Salomão. Por sua vez, ela é entregue ao novo associado da religião, através de uma cerimônia simples, denominada Fardamento. A farda é um outro símbolo significativo de destaque na religiâo daimista, por distinguir os seus adeptos dos visitantes. (OLIVEIRA, 2007, p. 223-228).

Cabe mencionar que fazem parte da doutrina daimista os hinários, em destaque o "Hinário o Cruzeiro", do Mestre Irineu. É notória a presença da bricolagem do cristianismo no conteúdo dos hinos entoados durante os rituais, nas datas principais dos trabalhos, nas preces que são feitas no início e no encerramento dos rituais, como, por exemplo, o Pai Nosso, a Ave Maria e a Salve Rainha, e também a prática de se rezar o Terço antes dos rituais mais longos. (OLIVEIRA, 2007, p. 64).

Agregando-se aos símbolos já mencionados, tem-se, como a essência do culto, o Daime, o chá milagroso: "Eu tomo esta bebida. Que tem poder inacreditável", como se diz no hino no 124, do próprio fundador, e tem a sua divulgação nas narrativas orais sobre as curas alcançadas pelo seu uso religioso. Daí, foi se formando um imaginário daimista, que associa a ingestão do chá ao universo simbólico do sagrado e do cristão. Então, como já assinalado, aos poucos, o chá foi sendo percebido como santo. Inclusive, ao nome original, com o transcorrer do tempo, acrescentou-se o adjetivo "Santo", como prova desse amplo processo de ressignificação, passando a ser denominado "Santo Daime". (OLIVEIRA, 2007, p. 196-197).

No entanto, é importante esclarecer que, durante as primeiras experiências visionárias do Mestre Irineu junto à comunidade indígena, na floresta, até a década de 1930, a bebida ainda era chamada de Ayahuasca, ou Huasca, uma distorção da palavra original. Por outro lado, o cipó era chamado de Mariri e a folha, Chacrona ou Mescla. Mas, a partir da compreensão gradativa do Mestre Irineu sobre a Ayahuasca e de suas vivências culturais, se deu a elaboração dos novos nomes dos componentes da bebida. Entáo, o cipó foi rebatizado como "Jagube", a chacrona; a folha foi denominada como Rainha e o chá, a bebida indígena, passou a ser chamada pelo nome de Daime. Assim sendo, esses elementos ressignificados, de acordo com a concepção daimista, remetem à união primordial do Mestre Irineu com a "Rainha da Floresta", a "Virgem Maria”, presente nos mitos fundadores da religiáo daimista. (OLIVEIRA, 2007, p. 234).

Oliveira evidencia que o Feitio do Daime, a sua preparaçáo, se tornou a principal prática ritualizada, em cuja realizaçáo os adeptos daimistas encontram um sentido espiritual e psicológico, reafirmando sua compreensão de que a bebida é um veículo sagrado e sacramental, semelhante ao sacramento cristáo, ao mesmo tempo em que conserva a sua qualidade. (OLIVEIRA, 2007, p. 233).

Ao afirmarem que "o Daime é o Mestre", os seguidores do Santo Daime identificam o Mestre Irineu como sendo o próprio Cristo e a ingestão ritualística da bebida passa a ser compreendida como um sacramento eucarístico. Em outras palavras, ao beber o Daime, os 
adeptos da religião do Santo Daime concebem estar comungando o próprio Cristo, na convicção de ser o Mestre Irineu. Então, nessa perspectiva, compreendem-se esses significados, como o próprio Daime, como elementos primordiais, que construíram a concepçáo de ser essa bebida um sacramento eucarístico cristão. (OLIVEIRA, 2007, p. 237).

Nesse contexto, o hino no 111: "ESTOU AQUI", do Mestre Irineu, o identifica como o próprio Jesus Cristo e refere a si mesmo como Juramidam: "Estou aqui [...] / Aqui findei / Faço a minha narração / Para sempre se lembrarem / Do velho Juramidam ${ }^{13}$ ". (OLIVEIRA, 2007, p. 239). A sua identificaçáo com Cristo pode ser percebida com clareza, através de seu hino no11: "UNAQUI": "Estou aqui, / Foi Deus do céu quem me mandou / Sou filho da Virgem Mãe / Lá no céu Jesus Cristo Salvador", bem como no hino no 116: "SOU FILHO DO PODER": "Sou filho do poder / E dentro desta casa estou / Fazendo os meus trabalhos / Que minha mãe me ordenou.” (MATOS DA SILVA, 1994).

Vale dizer que, na religião daimista, existe uma compreensão compartilhada de que o Mestre Irineu é a reencarnação de um mesmo espírito que se manifestou na terra como Buda, que é pouco difundida, mas a ideia de ser uma reencarnação de Jesus Cristo é mais disseminada; e finalmente como Juramidam. Dessa maneira, a concepção daimista de que o Mestre Irineu seja uma reencarnação de Jesus Cristo pode ser considerada como um dado relevante, por associar a religiáo do Santo Daime "não apenas no contexto da história Cristã, mas no âmbito mais amplo das expressóes religiosas que se manifestaram ao longo da História da humanidade". (OLIVEIRA, 2007, p. 245).

Sendo assim, pela convicção dos seguidores daimistas de que a ingestão do Daime é um sacramento, compreende-se, com clareza, a adoção da expressão atual "substância enteógena", derivada de entheos, de origem grega, que significa literalmente "deus dentro". Portanto, enteógeno significa aquilo que leva alguém a ter o divino dentro de si. Isso vai além de conceber o Daime somente como uma "substância psicoativa”. (MACRAE, 1992, p. 16).

Enfim, diante dos sistemas simbólicos, o sociólogo Berger (2004) compreende a importância dos rituais e dos símbolos como instrumentos de "rememoramento", ou seja, como a atualização do mito, dizendo:

Os homens esquecem. Precisam, por isso, que se lhes refresque constantemente a memória. Aliás, pode-se alegar que um dos mais antigos e importantes pré-requisitos para o estabelecimento da cultura é a instituição desses "lembretes" [...]. O ritual religioso tem sido um instrumento decisivo desse processo de "rememoramento". Repetidas vezes "torna presente" [atualizam] aos que nele tomam parte as fundamentais definiçóes da realidade e suas apropriadas legitimaçôes". (BERGER, 2004, p. 53).

\footnotetext{
${ }^{13}$ A palavra Juramidam se refere à nova compreensão que Mestre Irineu alcançou de si mesmo, antevendo a sua existência na realidade espiritual. Para os daimistas, as pessoas têm um nome "na terra" e outro "no astral". Midam seria, inclusive, o nome de uma família na realidade espiritual. Portanto, Juramidam seria o nome do Sr. Irineu no astral ou realidade espiritual. (OLIVEIRA, 2007).
} 


\section{Intolerância e divisóes internas na doutrina daimista originária}

Como já abordado, após a morte do Mestre Irineu, o Padrinho Sebastião entrou em conflito com a nova liderança do CICLU/Alto Santo, culminando com o seu rompimento com o grupo damista originário. Por isso, ele formou seu próprio centro, o CEFLURIS, em 1974, localizado às margens do Igarapé do Mapiá (no Amazonas), que, no ano de 1998, foi renomeado como Igreja do Culto Eclético da Fluente Luz Universal (ICEFLU). (ASSIS; LABATE, 2014, p. 14).

O conflito entre Leôncio, líder do CICLU, e o Padrinho Sebastião pode ser explicado, dentro da visão de Bourdieu (1992), como a existência de tensóes, de lutas por poder, dentro de cada campo religioso. Isso se manifesta, por exemplo, quando novas pessoas, com novas ideias, buscam legitimar sua posição em relação a um grupo ou a uma normativa dominante, que, por sua vez, tenta defender a sua posição, excluindo a concorrência e não legitimando o novo. (OLIVEIRA, 2011, p. 159).

A nova vertente agregou novos elementos aos rituais herdados do Mestre Irineu, como a aproximaçáo com o espiritismo kardecista e com as religióes afro-brasileiras, no que concerne a incorporações de espíritos nos rituais. Na visão da vertente CICLU, não se permitem mudanças ou novidades na doutrina daimista originária, permanecendo restrita, quase que totalmente, ao Norte do país. (ASSIS; LABATE, 2014, p. 14).

Portanto, o CEFLURIS/ICEFLU se distingue do CICLU por ter uma característica plural, com abertura para a inserçáo dinâmica de novos elementos ritualísticos, o que possibilitou atingir uma expansão nacional e internacional, tendo o Céu do Mapiá como o maior agrupamento daimista mundial. Após a morte do Padrinho Sebastião, em 1990, a direção da doutrina ficou a cargo de seu filho, Alfredo Gregório de Melo, conhecido como Padrinho Alfredo, que deu continuidade à consolidação da religião do Santo Daime e sua expansão pelo Brasil e pelo mundo. (ASSIS; LABATE, 2014, p. 22; OLIVEIRA, 2007, p. 35).

Miranda afirma que, atualmente, existem igrejas do Santo Daime em vários lugares da América do Sul, nos Estados Unidos, Canadá, Japão, Holanda, Espanha, França, Itália e em vários outros países. (MIRANDA ${ }^{14}, 2020$ ).

De certa forma, pode-se dizer que o Daime deixou de ser uma organização relativamente homogênea, passando por um processo que tem se intensificado cada vez mais, se tornando como uma religião institucionalizada, conhecida como Santo Daime. (ASSIS; LABATE, 2014, p. 14).

Cabe evidenciar que, segundo Oliveira (2011), a partir da década de 1930, formaramse novos contextos de utilização da bebida denominada Ayahuasca (Daime) e se constituíram algumas religiôes, tidas como cristãs, segundo seus adeptos, que passaram, também, a utilizá-la ritualisticamente. Entre essas religiōes, encontram-se o Santo Daime, a Barquinha e a União

\footnotetext{
${ }^{14}$ Claudio José Miranda é mestre em Filosofia, professor de Estudos Comparados de Religião e membro da Comissão de Combate à Intolerância Religiosa.
} 
do Vegetal, que buscam, cada qual, construir sua legitimidade própria, assumindo diferentes posiçóes políticas e ideológicas nesse campo (BOURDIEU, 2004, p. 89). Assim sendo, o Mestre Irineu começou a reunir ao seu redor alguns seguidores e, até o seu falecimento, estruturou os principais rituais, símbolos e preceitos doutrinários da religiáo daimista. Oliveira destaca que, no final da década de 1940, o Mestre Irineu ofereceu ao seu discípulo, o Sr. Daniel Pereira de Matos, a possibilidade de fundar outra linha de trabalhos espirituais associada ao uso do Daime, linha essa conhecida como a Barquinha. Porém, o Mestre manteve intacta a sua doutrina CICLU. (OLIVEIRA, 2011, p. 168).

Com o surgimento da Barquinha, entre as décadas de 1930 e 1960, segundo Galvão (1955, p. 146 apud OLIVEIRA, 2011, p. 168) e Goulart (1966, p. 140 apud OLIVEIRA, 2011, p. 168), houve uma grande transformação histórica e social no âmbito da religiosidade popular brasileira, na região amazônica. $O$ processo de legitimação das práticas religiosas afrobrasileiras e das práticas vegetalistas tradicionais na Amazônia, segundo Oliveira, ocorreu devido à adoção das concepçôes kardecistas e da sedimentação dessas práticas religiosas populares.

Cabe aqui ressaltar que, segundo Menezes, afirmar o "Direito sagrado de divergir" é negar a quem quer que seja - em especial ao Estado e às maiorias - "o direito de reprimir a diversidade alheia, de perseguir os dissidentes, de tentar reduzir pela força as divergências". (MENEZES, 1996, p. 6).

Segundo Oliveira, à medida que se difundiu, entre os adeptos daimistas, a ideia de que há um ser divino presente na bebida Ayahuasca ou o Daime, substância enteógena, e que esse ser divino era o próprio Mestre Irineu, que foi, por sua vez, identificado pelos daimistas como o Cristo, foi se reconfigurando a ressignificação da Ayahuasca até o seu sentido atual. Ainda de acordo com essa autora, essa ressignificação encontra-se presente nos hinos cantados durante os rituais daimistas. (OLIVEIRA, 2011, p. 156).

Assim sendo, afirma Oliveira (2007):

Ao ingerir o Santo Daime, as pessoas cantam os hinos. Ao cantá-los sob o efeito psicoativo da bebida, fazem uma releitura do seu significado, a partir da vivência e condição psicológica de cada pessoa. Ao estabelecer um diálogo com esse conteúdo, constrói-se uma leitura particular da vivência psicoativa com a ayahuasca na religião, ao mesmo tempo em que se constitui uma leitura do conteúdo expresso nos hinos, condicionada pelo presente. Esse diálogo interior estabelecido entre as pessoas e os hinos também subsidia o surgimento de novas compreensóes sobre os princípios doutrinários da religiáo, que são, entâo, objetivados em novos hinos. Quando esses novos hinos são cantados nos trabalhos espirituais do Santo Daime, consolida-se o processo de objetivação desses novos conteúdos que, por sua vez, contribuem para o processo contínuo de formação da religiáo (OLIVEIRA, 2007, p. 75).

Oliveira aponta que existem 4 (quatro) centros distintos do CICLU na regiáo do Alto Santo. Entre eles, encontra-se a própria Sede, erguida pelo fundador, na década de 1940. Devido à proximidade geográfica entre eles e sua pequena expansão para outras cidades do país, às vezes, compartilham certa afinidade ideológica e política acerca da condução da religião daimista atual, 
naquela regiáo. Sendo assim, os daimistas ortodoxos do Alto Santo compreendem que, para se conhecer a doutrina do Daime, tal como ela é, desde sua origem, as pessoas de outros estados, ou outros países, devem se deslocar de onde residem até o Rio Branco. E, dessa maneira, lá, devem vivenciar as práticas daimistas nos moldes deixados pelo Mestre Irineu. Essa opinião se funda na concepção de que a religião, com suas práticas e filosofia, deve permanecer inalterada ao longo do tempo, remetendo única e exclusivamente ao conjunto simbólico instituído pelo Mestre Raimundo Irineu. (OLIVEIRA, 2011, p. 157-158).

MacRae (1992) enfatiza que o Padrinho Sebastião, fundador do CEFLURIS/ICEFLU, foi uma das lideranças que mais se destacaram após o falecimento de Mestre Irineu. Ele nasceu no Seringal Monte Lígia, em Eirunepé (Amazonas), e teve contato com a religião do Mestre Irineu na década de 1960, quando foi curado de uma enfermidade graças ao Daime. Seguidores antigos dessa vertente daimista relatam que ele, de maneira natural, desde a infância, possuía dons mediúnicos, como a incorporação de espíritos e a projeção astral, compreendidos por seus adeptos como capacidades especiais que legitimam sua liderança espiritual. (OLIVEIRA, 2011, p. 159).

Nas tensóes geradas entre os diferentes grupos que compóem a religiáo daimista, envolvendo as partes política e social dessas instituições, destacam-se: a discussão sobre o consumo de outras substâncias psicoativas, a incorporação de espíritos, as transformaçôes e acréscimos nos rituais constituídos pelo fundador. Normalmente, os centros filiados ao CICLU/ Alto Santo não aceitam a possibilidade de consumo de outras substâncias psicoativas por parte de seus seguidores, nem durante os rituais daimistas, nem no âmbito de sua vida privada. Essa posição é baseada nos relatos orais de antigos seguidores, acerca da história da religiáo e da vida do fundador, bem como através das descriçôes prescritas no estatuto deixado pelo próprio Mestre Irineu, pouco antes de sua morte. (OLIVEIRA, 2011, p. 161).

Portanto, essas discordâncias sobre as concepçôes do que pode ser considerado legítimo, ou não, na religião do Santo Daime, é que causam as tensóes internas no campo religioso daimista. Isso acaba por gerar a intolerância religiosa entre seus seguidores e as organizaçóes que fazem o uso do Daime (Ayahuasca) e que se consideram, cada qual, sob a sua visão, uma vertente lícita da doutrina fundada pelo Mestre Irineu. (OLIVEIRA, 2011, p. 169).

O sociólogo Berger (1985) compreende a religião como um produto de construção humana, histórica e social, que viabiliza um certo ordenamento expressivo para os seus adeptos. Ele evidencia que as práticas e os hábitos humanos vão se modificando, influenciados pelo tempo. Então, a partir da época de suas produçóes, e a cada instante, são recriados, reinventados ou ressignificados. Dessa maneira, torna-se muito difícil fazer com que os rituais daimistas, em uma visão expansionista, permaneçam inalterados desde a época do seu surgimento, seguindo fielmente as orientaçóes e o legado estabelecido pelo Mestre. Isso porque as condiçóes atuais sempre remetem a uma releitura do passado, como no caso da vertente do Padrinho Sebastiáo, cujas ressignificaçóes e alteraçóes rituais favoreceram a exportação da religião daimista. (OLIVEIRA, 2011, p. 170). 
À vista disso, a compreensão compartilhada de que o "Mestre Irineu é e está no Daime", para a maioria dos adeptos daimistas, ameniza um pouco a polêmica estabelecida entre a concepção de uma doutrina imutável (ortodoxa) e uma doutrina viva e em expansão. Vale lembrar que o próprio fundador, o Mestre Irineu, durante a sua caminhada com o Daime, implantou muitas mudanças na religião. Assim sendo, o Padrinho Alfredo, atual líder do ICEFLU, em um de seus hinos, diz que se deve "Seguir realmente a doutrina / E não alterar nenhum til”. (OLIVEIRA, 2011, p. 171).

Por outro lado, aspectos políticos e idealistas envolvendo a continuidade da religiáo e a legitimação das lideranças atuais do Santo Daime são levados em consideração nas discussões. Mesmo diante da posição imutável da manutenção das práticas estabelecidas pelo Mestre Irineu, elas passaram a ser compreendidas como sendo aparentemente normativas. Então, na perspectiva de legitimar as autoridades daimistas, por meio da manutençáo do Daime e a acolhida de que as novas concepçóes sejam legítimas, tais práticas podem ser compreendidas também como normativas. Dessa maneira, seria plausível admitir algumas transformaçóes na religião daimista desde que tivessem o aval dos seguidores da doutrina. Com isso, se buscaria um esforço em se manter os elementos essenciais originários da doutrina, com a permanência do passado e a legitimaçáo da autoridade presente dos líderes atuais do Santo Daime. A concepção do Santo Daime como uma doutrina viva e em expansão e a admissáo da legitimidade da condução da religiáo daimista pelas lideranças atuais e da comunidade como detentora dos elementos presentes, herdados do passado, fortalecem a doutrina, tanto em poder, como em responsabilidade social, em função de suas atitudes. A partir dessa visão normativa do sagrado, se permitiria que a autoridade presente se fundamentasse nas construçóes mítico-fundadoras manifestas na oralidade. (OLIVEIRA, 2011, p. 171-172). Assim sendo, é importante lembrar o que diz Binoche (2010): "Nenhuma comunidade humana é de fato viável se seus membros não estiverem de acordo sobre certas "crenças" comuns (dogmas religiosos, preconceitos costumeiros, ideologias, valores compartilhados etc.) [...].” (BINOCHE, 2010, p. 24).

\section{As intolerâncias no Brasil e no exterior enfrentadas pela religiáo do Santo Daime}

Como já aludido, a visão externa, ou seja, de fora da religião daimista, leva a concepçôes preconceituosas, perseguição, aversão e repressão por conceber o Daime (a Ayahuasca) como uma substância alucinógena, pertencente ao grupo das drogas. Por esse motivo, a falta da devida compreensão do seu uso sacramental, nos rituais da religião do Santo Daime, motivou inúmeras intolerâncias e hostilidades em várias partes do mundo, como se segue.

\subsection{No Brasil}

A intolerância religiosa em nosso país não é um fato recente, visto que já vem 
desde o início da colonização portuguesa, quando chegou ao Brasil, juntamente com a religião hegemônica católica. Porém, a delimitação deste estudo se restringe à intolerância mediante a presença da religião do Santo Daime, dentro do país.

\subsubsection{Uma breve descrição cronológica dos fatos antagônicos e de seus avanços}

a) Desde 11 de outubro de 1890, estava em vigência uma política oficial de repressão à feitiçaria, tida como a prática ilegal da medicina, da magia, e que proibia o curandeirismo e o uso de "substâncias venenosas", baseada nos Artigos 156, 157 e 158 do Código Penal da época. Evidencia-se que esses artigos poderiam ser usados contra o Mestre Raimundo Irineu e, de fato, o foram. Porém, segundo MacRae (1992), a perseguição movida contra os terreiros e outros centros não era homogênea e certas casas conseguiam a proteção das autoridades locais: suas atividades eram registradas dentro do status de religiáo e, por isso, ficavam fora da intervenção policial. (MACRAE, 1992, p. 65);

b) Em 1985, a Divisão de Medicamentos do Ministério da Saúde - (DIMED), por conta própria e sem a devida anuência do Conselho Federal de Entorpecentes - (CONFEN), incluiu o cipó (Banisteriopsis caapi) ${ }^{15}$ na lista de produtos de uso proscrito (proibido) no território nacional. (MACRAE, 1992, p. 79);

c) Em 1986, o Conselho Federal de Entorpecentes - (CONFEN) nomeou uma delegação incumbida de avaliar o uso ritual do Daime (Ayahuasca). Então, após verificaçôes e análises, o resultado do trabalho culminou na liberação, em 1987, do uso do chá sacramental (Daime/Ayahuasca) somente para fins religiosos. (MACRAE, 1992, p. 86). Porém, em 1992, essa liberação foi reexaminada e mantida a decisão anterior do (CONFEN - 1987). (ASSIS; LABATE, 2014, p. 23);

d) Em 1998, com a criação do Conselho Nacional de Política sobre Drogas, atualmente, Conselho Nacional Antidrogas (CONAD), que substituiu o CONFEN, elegeu-se uma nova comissão mista para rever novamente a questão considerada polêmica. Então, em 2004, foi estabelecido o Grupo Multidisciplinar de Trabalho sobre a Ayahuasca (GMT), composto por especialistas sobre drogas, bem como por representantes de diversos grupos que fazem o uso da Ayahuasca no rito religioso. Em 2006, o parecer do GMT foi concluído, porém, só em 2010, foi incluído na Resolução no 1 do CONAD. A Resolução no 1 (2010) tornou-se o principal documento que regulamenta e legaliza o uso da Ayahuasca nos ritos religiosos no Brasil. É importante destacar que o CONAD levou em consideração o posicionamento do Conselho Internacional de Controle de Narcóticos (INCB, sigla em Inglês), da ONU: "que afirma não ser esta bebida nem as espécies vegetais que a compóem objeto de controle internacional" (RESOLUÇÃO No1, 2010), embora a N.N-dimetiltriptamina (DMT) ${ }^{16}$ esteja proscrita na Convenção de Viana (1971). Assim sendo, essa decisão sobre o emprego

\footnotetext{
15 O chá (Ayahuasca/Daime) é feito a partir do cozimento do cipó jagube ou Mariri (Banisteriopsis caapi) e da folha da Chacrona (Psychotria viridis), plantas nativas da bacia Amazônica.

16 DMT é o principal agente psicoativo presente na folha da chacrona.
} 
da Ayahuasca dentro do Brasil, de certa forma, poderia influenciar decisóes quanto ao seu uso no exterior, mas não foi bem assim, pois, em cada contexto, prevaleceu a sua política sobre a sua legalidade. (ASSIS; LABATE, 2014, p. 23);

e) Em 2020, a deputada Jéssica Sales (MDB-AC) propôs, na Câmara dos Deputados, o Projeto de Lei 179/20, que tem por objetivo regular o uso da Ayahuasca no Brasil, dando o status de religião para o Santo Daime. Ela diz que busca formalizar juridicamente as instituiçóes que utilizam a Ayahuasca como sacramento de seus cultos e rituais, o que seria fundamental para o reconhecimento de direitos, como a imunidade tributária, prevista na Constituição, para igrejas. Assim sendo, ficam assegurados o livre exercício das atividades e manifestaçôes ligadas ao chá e a proteção aos locais de culto e às suas liturgias. As instituições terão o prazo de, no máximo, até 180 dias para solicitarem a formalização jurídica como organizaçóes religiosas. A Deputada Jéssica explicou que essa formalização trará mais segurança às instituiçóes que empregam Ayahuasca em seus cultos, dando-lhes maior responsabilidade e identidade. Segundo ela, isso "vai diferenciar o que é legítimo e protegido pelo Estado daquelas pseudo-entidades que fazem o mau uso do chá, muitas vezes relacionando seu uso a práticas recreativas ou outras que nada têm a ver com o legítimo exercício da religiáo". De acordo com essa proposição, passa a ser permitido, em todo o território nacional, nos locais previamente autorizados, a ingestão do chá sacramental. A proposta tem também a disposição de regular o cultivo e a coleta das espécies vegetais que formam o chá, incluindo o seu preparo, armazenamento e ministração. Porém, proíbe que essas práticas sejam feitas com o intuito de obter lucro ou a associação do chá com outras substâncias psicoativas. (CÂMARA DOS DEPUTADOS, 2020);

f) Miranda (2020) enfatiza que, a partir do ano de 2020, a doutrina do Santo Daime passou a ser parte integrante da Comissão de Combate à Intolerância Religiosa (CCIR), inicialmente, devido aos constantes ataques sofridos por pessoas que, de forma equivocada, consideram o sacramento do Daime (Ayahuasca), de caráter sagrado e natural, como droga, isto é, de uma forma depreciativa. Além disso, a doutrina do Santo Daime junta-se a todas as outras religióes que se colocam à frente de uma luta contra os ataques de forças reducionistas, que querem eliminar as outras formas de espiritualidade da vida do povo brasileiro. (MIRANDA, 2020).

\subsubsection{Uma visáo daimista sobre a tolerância religiosa}

A concepção da vertente do Santo Daime, o ICEFLU, com relação à tolerância religiosa, preconiza o seguinte:

Concordamos em praticar abertura e respeito pelas pessoas cujas crenças são contrárias às nossas. Compartilhamos os ensinamentos do Santo Daime com aqueles que procuram este caminho e estas verdades ao mesmo tempo em que reconhecemos que fazer proselitismo é proibido. Para ajudar a salvaguardar contra as consequências nocivas da ambição pessoal e organizacional, evitamos a promoção ativa da Igreja. (ICEFLU, 2020). 
Por outro lado, com relação ao diálogo inter-religioso, ao ecumenismo e às alianças, o ICEFLU divulga o seguinte:

Dentre as diversas linhas espirituais Ayahuasqueiras e daimistas, sem dúvida, temos um viés bastante universalista no que diz respeito a abertura para o diálogo e a prática [inter-religiosa]. Isto nos foi legado pelo Padrinho Sebastião, que sempre recebeu representantes de outras tradiçóes religiosas sem qualquer tipo de preconceito, incentivando sempre o respeito, o diálogo e o ecumenismo. (ICEFLU, 2020).

\subsection{No exterior}

A intolerância religiosa com relação à exportaçáo da doutrina do Santo Daime de origem brasileira para outros países não ocorreu de uma forma homogênea, tendo uma atitude peculiar adotada em cada país, segundo as regras pré-estabelecidas no trato da interpretação do Daime como uma substância pertencente ao grupo das drogas. Percebeu-se também que aquilo que foi interpretado no Brasil, país de origem da religião daimista, não serviu de referência para os outros países.

\subsubsection{Uma breve descriçáo cronológica dos fatos iniciais ocorridos no exterior e os seus desfechos}

a) A presença da DMT no chá sacramental daimista tornou-se objeto de vários debates na esfera legal, visto que a Convenção sobre Substâncias Psicotrópicas (CSP) das Organizaçóes das Nações Unidas (ONU - 1971) a considerou como uma das substâncias proscritas de nível 1, como o LSD, o Ecstasy e a Mescalina. Porém, enfatiza-se que a DMT não é manipulada, e sim, obtida através de substâncias naturais. Daí a discussão sobre a Ayahuasca ser ou não enquadrada como uma substância alucinógena, como determinou a CSP. (ASSIS; LABATE, 2014, p. 13);

b) No ano de 1990, surgem os primeiros problemas de ordem legal quanto à prática do Santo Daime, nos Estados Unidos da América (EUA) (Cf. GOISMAN, 2013 apud ASSIS; LABATE, 2014, p. 19);

c) Em 1994, uma das primeiras investidas das autoridades contra a religiáo do Santo Daime, na Europa, foi na Alemanha. (Cf. ROHDE; SANDER, 2011 apud ASSIS; LABATE, 2014, p. 20);

d) Assis e Labate (2014), em pesquisa de campo, afirmam que, em 1999, dois daimistas dos EUA foram detidos por autoridades norte-americanas (ASSIS; LABATE, 2014, p. 20). Nesse mesmo ano de 1999, na Holanda, foram presos dois líderes holandeses do Santo Daime, enquadrados pela lei holandesa antidrogas. Nessa mesma época, segundo Rohde e Sander (2011 apud ASSIS; LABATE, 2014), na Alemanha, foi registrada uma intervenção 
policial com um contingente de 100 policias, fortemente armados, em um acampamento do Santo Daime. (ASSIS; LABATE, 2014, p. 20);

e) $\mathrm{Na}$ Europa, em 2000, especificamente na Espanha, membros do Santo Daime foram detidos. E, no decorrer do ano de 2004, na Itália, foram confiscados, pelas autoridades italianas, em torno de trinta litros de Daime, sacramento ritualístico daimista. No ano seguinte, aproximadamente vinte seguidores do Santo Daime foram presos, gerando repercussão na mídia local, que noticiava, de forma a chocar a sociedade, que o Santo Daime se tratava de uma seita demoníaca, originada da magia negra, e que usava rituais orgiásticos. (Cf. MENOZZI, 2011 apud ASSIS; LABATE, 2014, p. 20);

f) Em 2007, segundo Watt (2013 apud ASSIS; LABATE, 2014), foi detido um líder do Santo Daime na Irlanda, por estar portando certa quantidade de Ayahuasca (ASSIS; LABATE, 2014, p. 20);

g) Em 2011, na Bélgica, tem-se o registro da apreensão de aproximadamente cinquenta litros do sacramento daimista. (Cf. BLAINEY, 2013 apud ASSIS; LABATE, 2014, p. 20).

\subsubsection{Uma breve descriçáo cronológica dos avanços ocorridos no exterior}

a) A partir de junho de 2002, na Espanha, após a não obtenção de uma resposta, por mais de seis meses, ao pedido de inclusão do Santo Daime no registro de organizaçôes religiosas, de acordo com a legislação espanhola, a religião daimista acabou sendo reconhecida como entidade religiosa, diante desse "silêncio administrativo" (Cf. LÓPEZ-PAVILLARD; DE LAS CASAS, 2011 apud ASSIS; LABATE, 2014, p. 24);

b) Em 2009, o governo italiano, segundo Menozzi (2011 apud ASSIS; LABATE, 2014), permitiu o emprego da Ayahuasca no culto do Santo Daime, até então, proibida pela lei italiana de substâncias controladas (ASSIS; LABATE, 2014, p. 24);

c) Nos EUA, no estado de Oregon, em 2009, segundo Labate e Feeney (2012), os rituais daimistas foram autorizados de forma legítima (Cf. LABATE; FEENEY, 2012 apud ASSIS; LABATE, 2014, p. 24);

d) Em 2012, a Corte Superior de Amsterdã, na Holanda, emitiu um parecer favorável sobre a liberdade do emprego do Daime nos cultos daimistas. Enfatiza-se que tal parecer se baseou na Convenção Europeia dos Direitos Humanos (European Court of Human Rights - ECHR), com relação à liberdade religiosa e, dessa maneira, sobrepôs a proibição internacional do DMT, bem como a corte holandesa sobre drogas, Corte de Apelaçôes de Amsterdã (2012), processo número: 23-001916-09. (Cf. CORTE DE APELAÇÔES DE AMISTERDÃ, 2012 apud ASSIS; LABATE, 2014, p. 24).

Enfim, a indefinição quanto à legalidade do Santo Daime em países como Alemanha, Bélgica, Irlanda e França não acarretou a extinção dos cultos daimistas ou a adesão à religião. Porém, essa condição irresoluta promove a dispersão e a clandestinidade dos grupos seguidores, tornando o controle da utilização da Ayahuasca mais difícil e menos organizado. E esse fato é 
agravado, principalmente, devido ao exílio das lideranças do Santo Daime. (ASSIS; LABATE, 2014, p. 24).

\section{Conclusão}

Levando-se em conta o que foi observado, pode-se destacar que a religião do Santo Daime é constituída basicamente de uma bricolagem de elementos da tradição indígena e da tradição cristã e que, após a morte de seu fundador, em 1971, se transformou em duas vertentes: a CICLU, doutrina original, ortodoxa, do Mestre Irineu Serra; e a CEFLURIS/ICEFLU, do Padrinho Sebastiáo, que agregou à doutrina daimista elementos do espiritismo e da umbanda.

Assim sendo, o primeiro problema gerador de intolerância externa à religiáo do Santo Daime é a não compreensão exata do que seja o Daime (Ayahuasca), a bebida de origem xamânica, ou seja, a adaptação de um chá da tradição indígena dentro de uma tradição europeia. Para os daimistas, ela é uma substância psicoativa, enteógena, porém o senso comum a interpreta como uma droga, um alucinógeno. Outro problema é a ressignificação dos elementos da tradição cristã, religião hegemônica, dentro da doutrina do Santo Daime. Acrescenta-se, ainda, outro problema, que é a intolerância interna entre a compreensão da legitimidade da doutrina na visão do CICLU, que é a "manutenção do passado", ou seja, a imutabilidade, e a visão do CEFLURIS/ICEFLU, que considera a "doutrina viva" e em expansão, admitindo a atualização da doutrina, bem como a inserção de novos elementos e alteraçôes ritualísticas.

Dito isso, cabe ressaltar que o Santo Daime é uma religiáo de origem brasileira, de cultura essencialmente oral, com poucos registros escritos sobre seus fundamentos e sua história, ou seja, não é uma religiáo do Livro. Existem apenas registros orais importantes, que compóem o corpus semântico da religiáo, como, por exemplo: os hinos cantados nos rituais daimistas, as histórias de vida e os relatos de seus seguidores mais antigos, que relembram os fatos históricos mais marcantes da religiáo, que, por sua vez, explicam os fundamentos doutrinários da religião do Santo Daime. Então, apesar da existência das duas compreensôes antagônicas de legitimação da religiáo, entre os daimistas, ou seja, entre as vertentes, subsiste uma unidade que sobrepóe essas divergências normativas que cada vertente evoca. Tal unidade se revela na convergência do uso ritualístico sacramental do Santo Daime. Possivelmente, esse é um dos caminhos para a redução ou até a eliminação da intolerância e a supremacia do respeito pelas diferenças. Esse é um desafio vivido não só na religião do Santo Daime, mas dentro do campo religioso pósmoderno. Cabe lembrar que o próprio Mestre Irineu respeitava a diversidade religiosa quando, no final da década de 1940, ofereceu a possibilidade, ao seu discípulo Daniel Matos, de fundar outra linha de trabalhos espirituais com o Daime - que ficou conhecida como Barquinha -, mas a doutrina do Mestre permaneceu inalterada.

Por fim, a finalidade deste artigo é contribuir para a diminuição e uma possível eliminação das tensôes e intolerâncias internas e externas à doutrina do Santo Daime, fazendo prevalecer "o direito sagrado de divergir" e perceber as práticas de cada vertente como verdadeiras 
e legítimas, favorecendo, dessa maneira, um convívio de paz e respeito diante da diversidade das instituiçôes daimistas. Os avanços na compreensão do que seja a religião do Santo Daime fortalecerão a sua inserção dentro do contexto religioso ocidental.

Dito isso, um grande desafio para a compreensão e a boa convivência com a pluralidade religiosa, na contemporaneidade, seria a introdução da educação para a interculturalidade, como propóe Panikkar (2006), visando uma maior compreensão da importância da cultura oral versus a civilização de cultura escrita. Além disso, a interculturalidade é, antes de tudo, uma abertura para as outras culturas, bem como para facilitar o diálogo para uma educação mútua. (PANIKKAR, 2006).

Cabe aqui pontuar que este estudo não exaure o assunto em discussão, pois existem outras fontes de pesquisas acadêmicas disponíveis a respeito desse tema e que se revelam como um conjunto bibliográfico que abre novas perspectivas para outros estudos.

\section{Referências}

ASSIS, Glauber Loures de; LABATE, Beatriz Caiuby. Dos igarapés da Amazônia para o outro lado do Atlântico: a expansão e internacionalização do Santo Daime no contexto religioso global. Religiáo \& Sociedade, Rio de Janeiro, v. 34, n. 2, p. 11-35, 2014, .

BERGER, Peter. O dossel sagrado: elementos para uma teoria sociológica da religião. Luiz Roberto Benedetti (Org.). Trad. de José Carlos Barcellos. São Paulo: Paulus, 1985.

BINOCHE, Bertrand. Religião privada, opinião pública. In: SANTOS, Antônio Carlos dos (Org.). O outro como problema: o surgimento da tolerância na modernidade. São Paulo: Alameda, 2010, p. 24.

BOURDIEU, Pierre. Economia das trocas simbólicas. Sérgio Miceli (Org.). 5. ed. São Paulo: Perspectiva, 2004.

CÂMARA DOS DEPUTADOS. Projeto que regula uso da ayahuasca e dá status de religiáo para o Santo Daime em âmbito nacional (Fonte: Agência Câmara de Notícias 04/03/2020). Disponível em: https://www.camara.leg.br/noticias/640858-projeto-regula-uso-da-ayahuascae-da-status-de-religiao-para-o-santo-daime. Acesso em: 04 jan. 2021.

CENTRO DE DOCUMENTAÇÃO E MEMÓRIA - ICEFLU-Patrono Sebastião de Melo. Biografia do Mestre Irineu. Disponível em: https://www.santodaime.org/site/religiao-dafloresta/ mestre-irineu/biografiamestre. Acesso em: 04 jan. 2021.

COMUNIDADE DO ALTO SANTO. Madrinha Peregrina. Disponível em: https://www. facebook.com/pages/Comunidade-do-Alto-Santo-Irineu. Acesso em: 08 jan. 2021

MACRAE, Edward. Guiada pela lua: xamanismo e uso ritual da Ayahuasca no culto do Santo Daime. São Paulo: Brasiliense, 1992.

MATOS DA SILVA, Percília (1994). Hinário: o cruzeiro. Disponível em: https://www.mestre irineu.org/cruzeiro.htm. Acesso em: 20 jan. 2021. 
MENEZES, P. Filosofia e tolerância. Síntese nova fase. Belo horizonte, v. 23, n. 72. p. 5-11, 1996.

MIRANDA, Claudio José. A doutrina do Santo Daime. Comissão de Combate à Intolerância religiosa. 2011. Disponível em: https://extra.globo.com/noticias/religiao-e-fe/comissao-decombate-a-intolerancia-religiosa/a-doutrina-do-santo-daime-2173348.html. Acesso em: 20 nov. 2020.

MOREIRA, Paulo; MACRAE, Edward. Eu venho de longe: mestre Irineu e seus companheiros. Salvador: EDUFBA, 2011.

OLIVEIRA, Isabela. Santo Daime: um sacramento vivo, uma religião em formação. 2007. 290f. Tese (Doutorado em História) - Universidade de Brasília, Instituto de Ciências Humanas, Brasília, 2007.

OLIVEIRA, Isabela. Um desafio ao respeito e à tolerância: reflexóes sobre o campo religioso daimista na atualidade. Religiáo \& Sociedade, Rio de Janeiro, v. 31, n. 2, p. 154-178, 2011.

ORGANIZAÇÃO DAS NAÇŌES UNIDAS. Convention on Psychotropic Substances. 1971. Disponível em: http://www.unodc.org/pdf/convention 1971 en.pdf. Acesso em: 04 jan. 2021.

PANIKKAR, Raimon. Paz e interculturalidad: una reflexión filosófica. Barcelona: Herder, 2006.

RUSSO JR, Álvaro Antônio. Na boca da mata: diálogos entre Santo Daime e Umbanda. 2016, . Dissertação (Mestrado). Programa de Pós-Graduação em Antropologia Social da Faculdade de Filosofia, Letras e Ciências Humanas da Universidade de São Paulo, 2016.

RESOLUÇÃO DO CONAD No 1 de 25 jan. 2010. Dispóe sobre a observância, pelos órgáos da Administração Pública, das decisóes do Conselho Nacional de Políticas sobre Drogas CONAD sobre normas e procedimentos compatíveis com o uso religioso da Ayahuasca e dos princípios deontológicos que o informam. Norma Federal, publicada no DO em 26 jan. 2010. Disponível em: https://www.normasbrasil.com.br/norma/resolucao-1-2010 113527. html. Acesso em: 04 jan. 2021. 